\title{
L'apparition de la justice-bâillon au service de la cruauté illégale en France...
}

\author{
Sabine Brels ${ }^{1}$
}

Deux ordonnances des 9 et 16 juillet 2013 condamnent l'association L214 à une pénalité de plusieurs centaines d'euros en lui interdisant de diffuser des images dénonçant l'illégalité de deux élevages de poules pondeuses ${ }^{2}$. Un référé suppose une urgence. Quelle était l'urgence à statuer dans ce cas? Celle d'empêcher la diffusion d'images compromettantes sur des élevages fournissant une entreprise aussi importante que Matines dans la production d'œufs. En effet, ces images montrent de graves infractions à la réglementation européenne en vigueur (directive 1999/74/CE). Les poules pondeuses sont en surdensité dans les cages et les installations ne sont pas conformes $^{3}$. Il est également révélé que "certaines poules n'ont plus que quelques plumes sur le corps", que "des cadavres en décomposition avancée bloquent des œufs", et même que "des œufs et de nombreuses poules sont infestés de parasites"4.

Ces ordonnances imputent à l'association plusieurs méfaits dont le non-respect de la propriété et de la vie privée ${ }^{5}$. Notons pourtant qu'il s'agit bien moins d'un problème privé que d'un problème public et même d'un problème de société qui concerne la protection du bien-être animal et des consommateurs. De plus, notons que la vie privé des exploitants n'a aucunement été montré et que le droit à l'information des consommateurs est absent des considérations prises en compte dans les décisions rendues. De leur côté, les exploitants allèguent aussi la mise en danger des normes d'hygiène par les auteurs des vidéos qui se seraient introduits dans les élevages. Deux objections peuvent être soulevées. Tout d'abord, cet argument semble faible comparé à l'infection parasitaire des poules et des œufs. De plus, les images envoyées de manière anonyme à L214 (mais ne laissant aucun doute sur les élevages en cause),

\footnotetext{
${ }^{1}$ Doctorante française en droit animal, Université Laval (Québec), titulaire de la Bourse d'études supérieures du Canada Vanier.

${ }^{2}$ Ordonnance du 9 juillet 2013 concernant l'élevage sous contrat avec Matines exploité par la société Val Produits sur la commune de Branges en Saône-et-Loire et Ordonnance du 16 juillet 2013 concernant l'élevage sous contrat avec Matines exploité par le GAEC du Perrat sur la commune de Chaleins dans l'Ain.

${ }^{3}$ Conformément à la réglementation européenne en vigueur, les installations devraient comprendre des nids artificiels, perchoirs, litière pour le picotage et le grattage ainsi que des raccourcisseurs de griffes non conformes dans ces élevages.

${ }^{4}$ Voir sur le site de l'association L214 en ligne: http://www.1214.com/communication/20130724-elevages-Matinesimages-censurees.

${ }^{5}$ Voir les ordonnances précitées.
} 
auraient pu être "tournées par des employés de ces mêmes entreprises ne supportant plus la violence infligée à ces animaux destinés aux abattoirs pour être consommés ensuite"6.

Ainsi, la justice française semble suive l'exemple des États américains ayant adopté des "lois-bâillons". D'une manière générale, celles-ci visent à interdire et sanctionner la dénonciation vidéo par voie médiatique (Internet ou presse) de la cruauté illégale dans les élevages et les abattoirs. En effet, si les lois-bâillons ont été adoptées dans certains États américains (lowa, Kansas, Missouri, Montana, Dakota du Nord et Utah ${ }^{7}$ ), elles ont été rejetées dans d'autres (Indiana, Nebraska, New Hampshire, Nouveau Mexique, Pennsylvanie, Tennessee, Vermont, Wyoming et récemment la Caroline du Nord ${ }^{8}$ ). Ces derniers ont ainsi fait le choix de se prononcer en faveur de la liberté de dénonciation plutôt que pour la protection de la cruauté illégale, préférée par d'autres à des fins politico-économiques.

Notons qu' au Québec, il existe depuis 2009 une loi "visant à empêcher de grandes entreprises de museler des citoyens ou groupes impliqués dans le débat public", de sorte que cette province canadienne a été la première à légiférer en la matière ${ }^{9}$. II s'agit certainement d'un bel exemple démocratique à suivre!

Que ressort-il alors du cas français? Dans l'hypothèse où la protection de la corrida par le Conseil constitutionnel en septembre dernier n'aurait pas suffit à constituer à lui seul un précédent déplorable ${ }^{10}$, les récentes ordonnances qui bâillonnent les associations de protection viennent sans doute confirmer le caractère accablant de I'incohérence et de l'immoralité judiciaire. Ainsi, la France persiste et signe dans sa justice antiprotectionniste des animaux malgré l'injustice criante qui en résulte!

Il est possible de penser que la justice doit viser des finalités éthiques ou morales, comme la défense des opprimés, en allant vers toujours plus d'équité entre les êtres.

\footnotetext{
6 Voir en ligne: http://blogs.mediapart.fr/blog/jaquis/260713/quand-linstitution-judiciaire-viole-ouvertement-lajustice.

${ }^{7}$ Ani B. SATZ"Gag the 'ag-gag' laws that bar undercover recording of cruelty to farm animals", July 5, 2013, en ligne: http://www.csmonitor.com/Commentary/Opinion/2013/0705/Gag-the-ag-gag-laws-that-bar-undercoverrecording-of-cruelty-to-farm-animals.

${ }^{8}$ Id. Voir aussi Matt RICE "Breaking News: North Carolina Ag-Gag Bill is Dead", July 26, 2013, en ligne: http://www.mfablog.org/2013/07/breaking-news-north-carolina-ag-gag-bill-is-dead.html.

9 Voir "Une loi contre les poursuites-bâillons", Radio-Canada.ca, 3 juin 2009, en ligne: http://www.radiocanada.ca/nouvelles/societe/2009/06/03/001-loi-anti-slapp-baillon.shtml.

${ }^{10}$ Voir par exemple à ce sujet S.BRELS, "Injustice et cruauté: la corrida constitutionnalisée”, Commentaire de la décision du Conseil constitutionnel français sur la corrida du 21 septembre 2012, Derecho Animal, septembre 2012, en ligne: http://www.derechoanimal.info/images/pdf/Article-sabine-corridas-francia.pdf.
} 
Or, la justice française confirme le contraire. Ce n'est pas la loi morale qui s'impose, mais la loi du plus fort. Celui qui détient le pouvoir économique ou politique gagne. Ceux qui veulent le dénoncer, aussi illégale que soit son action, doivent payer.

Ainsi en va-t-il de l'injustice française envers les animaux. Ceux qui dénoncent les actes illégaux sont punis, quand les coupables sont protégés. Ceux qui veulent protéger les êtres vulnérables doivent payer, quand les hors-la-loi gagnent de l'argent en plus d'être blanchis. Et quel argent? Celui des associations de protection. En d'autres termes, l'argent des citoyens bien intentionnés qui s'impliquent justement pour lutter contre la cruauté envers les animaux. Et où finit leur argent bienveillant en définitive? Dans la poche de ceux qui les maltraitent illégalement. C'est la justice à l'envers...

Refusons de nous taire face à tant d'injustice. Cette atteinte ouverte à la liberté d'expression enfreint une liberté bien plus importante encore: la liberté d'agir pour sauver les victimes d'actes cruels. Dans d'autres cas pourtant, il en va de la responsabilité des citoyens français de porter assistance aux animaux en danger. Par exemple, si un chien se trouve dans une voiture en plein soleil l'été et cherche son air, il faut appeler au plus vite les services de l'ordre (police, gendarmes ou pompiers) pour briser la vitre du véhicule et le sauver ${ }^{11}$. Même s'il s'agit d'une dégradation de propriété privée, cet acte est parfaitement légal dans ce cas ${ }^{12}$. Or, contrairement aux animaux de compagnie, les poules pondeuses sont considérées comme des machines à produire des œufs ou encore des produits de consommation, qui ne bénéficient pas de la même considération. Pourtant, elles disposent désormais d'un minimum de protection de la part des normes européennes. Celles-ci doivent être appliquées par les exploitants. Mais à l'image d'autres pays de l'Union européenne, la France est en retard dans sa mise en conformité, tout comme dans d'autres domaines touchant à la protection du bien-être anima $\left.\right|^{13}$.

Espérons que le juge qui statuera définitivement dans cette affaire rendra une décision plus juste au regard de tous les éléments évoqués. Quel que soit le pays concerné, il convient de réclamer une justice plus respectueuse des animaux et une application plus rigoureuse des textes censés les protéger. II en va de notre devoir d'être "humain" pour un avenir plus juste envers tous les êtres vivants...

\footnotetext{
${ }^{11}$ Pour un exemple récent voir: La voix du Nord, "Boulogne: la police libère deux chiens enfermés dans une voiture en plein soleil", 29.07.2013, en ligne: http://m.lavoixdunord.fr/region/boulogne-la-police-libere-deux-chiensenfermes-dans-une-ia31b49030n1443014.

${ }^{12}$ En plus de ne pouvoir contester le bris de glace aux services de l'ordre, les propriétaires peuvent être poursuivis pour maltraitance (Art. 521-1 du Code pénal) et sont passibles d'une contravention de seconde catégorie en vertu de l'article R.412-44 du Code de la route interdisant de laisser un ou plusieurs animaux seul(s) dans son véhicule.

${ }^{13}$ Voir en ligne: http://www.1214.com/non-application-reglement-protection-animaux. Voir aussi le rapport de l'OAV mentionnant que les élevages français de poules pondeuses ne disposent pas de litières réglementaires: http://ec.europa.eu/food/fvo/rep_details_en.cfm?rep_id=3068.
} 